\title{
Influence of tumor location on the composition of immune infiltrate and its impact on patient survival. Lessons from DCBCL and animal models
}

\section{Claire Galand ${ }^{1,2,3 \dagger}$, Sabrina Donnou ${ }^{1,2,3 \dagger}$, Thierry Jo Molina ${ }^{3,4}$, Wolf Herman Fridman $^{1,2,3}$, Sylvain Fisson ${ }^{1,2,5,6,7}$ and Catherine Sautès-Fridman ${ }^{1,2,3}$ *}

1 INSERM, UMRS872, Centre de Recherche des Cordeliers, Paris, France

${ }^{2}$ Université Pierre et Marie Curie-Paris 6, UMRS 872, Paris, France

${ }^{3}$ Université Paris Descartes, UMRS 872, Paris, France

${ }^{4}$ Service d'Anatomie Pathologique, Hôtel Dieu, Assistance Publique Hôpitaux de Paris, Paris, France

${ }^{5}$ Genethon, Evry, France

6 INSERM, U951, Evry, France

7 Université d'Evry Val d'Essone, UMRS 951, Evry, France

Edited by:

Jean-Pierre Abastado, Singapore Immunology Network, Singapore

\section{Reviewed by:}

Alessandra Nardin, Singapore Immunology Network, Singapore Nadege Bercovici, CNRS, France

\section{*Correspondence:}

Catherine Sautès-Fridman, INSERM, UMRS872, Immune

Microenvironment and Tumor, Centre de Recherche des Cordeliers, 15 rue de l'Ecole de Médecine, Paris F-75006, France.

e-mail: catherine.fridman@ crc.jussieu.fr

${ }^{+}$Claire Galand and Sabrina Donnou have contributed equally to this work.
Diffuse large B-cell lymphomas (DLBCLs) are heterogeneous diseases growing either in nodal or extranodal locations including the central nervous system. One key issue is to decipher the prognostic value of immune cells infiltrating these tumors as DLBCLs developing in sanctuaries are more aggressive than nodal DLCBLs. Here, we summarize available data from the literature regarding the prognostic values of the different immune cell types found in these two types of human primary tumors (i.e., nodal vs brain). In nodal DLBCLs, memory T-cells and dendritic cells (DCs) densities are of good prognostic value whereas the influence of regulatory T-cells (Tregs) is less clear, in accordance with other types of cancers. Data for primary central nervous system lymphomas are very sparse for these cell types. By contrast, $\mathrm{CD}^{+}$cytotoxic T-cells seem to be of poor prognosis in either location. Their presence is linked to a loss of $\mathrm{MHC}$ expression providing a possible immune escape mechanism for these tumors. Clearly, tumor-associated macrophages are not associated to a significant prognostic value even in the brain where they highly infiltrate the tumor. Animal models indicate some specific features of lymphoma developing in sanctuaries by comparison to splenic location, with a higher infiltration of Tregs and less DCs, most likely reflecting the immunosuppressive context of these organs. All these informations illustrate the high impact of the immune system on patient outcome, encourage the pursuit of the immune environment's analysis and of immunotherapeutic approaches.

Keywords: tumor localization, immune microenvironment, DLBCL, CNS, T lymphocytes, APC

\section{INTRODUCTION}

Around one third of all adult lymphomas are diffuse large B-cell lymphomas (DLBCL), the most common form of non-Hodgkin lymphoma (NHL) in Western countries. The primary location of this cancer is intranodal for $2 / 3$ of patients and extranodal for the remaining $1 / 3$ (Groves et al., 2000). Nonetheless, although the overall incidence of DLBCL $\left(8 / 10^{5}\right.$ individuals in 2006) has been increasing slightly, at a rate of about $1 \%$ per year (Flowers et al., 2010), the incidence of extranodal B-cell lymphoma is rising faster, at about $3-6.9 \%$ per year (Chiu and Weisenburger, 2003). In particular, the incidence of primary central nervous system lymphoma (PCNSL) has climbed by $224 \%$ in 20 years and this cannot be solely attributed to HIV progression (Chan,

Abbreviations: APC, antigen-presenting cell; CNS, central nervous system; CTL, cytotoxic T-lymphocyte; DLBCL, diffuse large B-cell lymphoma; MHC, major histocompatibility complex; NHL, Non-Hodgkin lymphomas; OS, overall survival; PCL, primary cerebral lymphoma; PCNSL, primary central nervous system lymphoma; PIOL, primary intraocular lymphoma; TIL, tumor-infiltrating lymphocytes.
2003). The aggressiveness of DLBCL differs strongly according to tumor location. Overall survival (OS) rates in patients with DLCBL in immune sanctuaries, such as the CNS and testis (5year OS: 30 and 48\%, respectively; Shibamoto et al., 2008; Zucca, 2008), are substantially lower than those in other types of extranodal DLCBL (5-year OS: 63-91\%) and in all DLBCL sites (5year OS: 54\%; Schaffel et al., 2007). DLBCL is currently treated by chemotherapy (cyclophosphamide, doxorubicin, vincristine, and prednisone, $\mathrm{CHOP}$ ) now combined with immunotherapy (Rituximab). PCNSL is usually treated with chemotherapy and methotrexate (Shibamoto et al., 2008).

The aggressiveness of DLBCL also depends on the tumor's molecular signature. Three DLCBL subtypes have been described by gene expression profiling: germinal center B-cell like (GCB), activated B-cell like (ABC or post-GCB) and PBML (primary B-cell mediastinal lymphoma; Alizadeh et al., 2000; Rosenwald et al., 2003). Survival of patients with the GCB subtype (5-year OS: $76 \%$ ) is significantly higher than that of those with the ABC subtype (5-year OS: 16\%) among patients treated with chemotherapy 
(Rosenwald et al., 2003) or R-CHOP (Jais et al., 2008; Lenz et al., 2008). PCNSLs belong mostly to the ABC subtype (Gurbuxani et al., 2009). One study reports that the molecular signature of extranodal DLCBL is characterized by a lower rate of genetic alterations targeting $18 \mathrm{q}$ ( $92 \%$ for nodal vs $53 \%$ for extranodal DLBCL; Lopez-Guillermo et al., 2005). Moreover, PCNSL and testis lymphomas are also characterized by numerous alterations in MHC gene expression that can impair the cellular immune response (Jordanova et al., 2003).

The density of immune cells in the microenvironment of primary non-lymphoid tumors, especially $\mathrm{T}$ and dendritic cells (DCs), has been associated with good prognosis in many solid cancers. Galon et al. (2006) demonstrated that a high density of $\mathrm{CD}^{+}$cells is positively correlated with better survival of patients with colorectal cancer. More recently they showed the involvement of memory $\mathrm{CD}^{+}$and $\mathrm{CD} 4^{+}$cells in this phenomenon (Pages et al., 2009). Studies of antigen-presenting cells (APCs) have also demonstrated a strong association between a high density of mature DCs and survival in patients with non-small-cell lung cancer (Dieu-Nosjean et al., 2008). Cellular organization is also very important as has been shown notably with the importance of tertiary lymphoid structures in non-lymphoid organs (Halle et al., 2009; Fridman et al., 2012). As a consequence, it could be conceivable that anti-tumor immune response is more efficient in nodal tumors, but it does not seem to be as simple at least in the DLBCL context (Kim et al., 2011). Regarding PCNSL, it often develops in immune compromised patients, suggesting a role of the immune system but the implications in terms of immune infiltrate are currently unknown.

There is ample evidence that immune cells infiltrate DLBCLs, either in nodal or extranodal locations. One key issue is to decipher the prognostic value of immune cells infiltrating nodal DLBCLs. The strikingly lower survival rates of patients with DLBCL developing in sanctuaries compared with those patients with nodal DLCBL, suggests that an immunosuppressive environment might harness tumor aggressiveness. We will first review the data available from the literature about the prognostic values of the different types of immune cells found in these two types of primary tumors in humans. Thereafter, we will discuss how available animal models have helped to address some of these questions.

\section{IMMUNE INFILTRATE \\ T-CELLS}

Lippman et al. (1990) showed that tumor-infiltrating T-cells are associated with a good prognosis for patients with DLCBL, and more specifically that the number of tumor-infiltrating lymphocytes (TILs) was associated with relapse-free survival (see Table 1). That study however, did not distinguish between the major subtypes of T-cells. Since then, numerous studies have attempted to determine the relation between each type of immune subpopulation and patient' survival.

\section{$C D 4^{+} T$-cells are essentially linked to a favorable prognosis}

Infiltrating $\mathrm{CD}^{+} \mathrm{T}$-cells accounting for more than $20 \%$ of cells in a biopsy specimen have been positively correlated with better OS for 98 patients with DLBCL (Ansell et al., 2001). The number of $\mathrm{CD}^{+}{ }^{+}$T-cells related to the total number of activated T-cells
$\left(\mathrm{CD}^{+}{ }^{+} \mathrm{HLA}-\mathrm{DR}^{+}\right.$cells) suggests that most of infiltrating T-cells were activated. The role of $\mathrm{CD}^{+}{ }^{+} \mathrm{T}$-cells is crucial in the antitumor immune response. They indeed recognize the antigenic peptide presented by APCs and then shape the immune response by differentiating into Th1, Th2, Th17, or Treg cells. They are necessary for full activation of $\mathrm{CD}^{+}$effector T-cells and therefore crucial for tumor elimination.

Several authors have described Foxp $3^{+}$regulatory T-cells (Tregs) in the microenvironment of nodal B-cell lymphomas (Riemersma et al., 2005; Yang et al., 2006; Lee et al., 2008). The prognostic value of these intratumoral Tregs vary according to the author, the sample preparation and the DLBCL classification (Table 1). Hasselblom et al. (2007) reported that Foxp3 expression had no influence on the OS of 195 patients while in a study of 96 patients, Lee et al. (2008) found that the prognostic value of high percentages of Foxp3-positive Tregs for OS was good. A third study highlighted the difference in prognosis between the GCB subtype and non-GCB DLBCLs (Tzankov et al., 2008). A higher density of Tregs was associated with a good outcome in GCB DLBCL (32/55 patients) and with a poor outcome in non-GCB DLBCL (28/70 patients). The ability of these cells to kill lymphoma B-cells depending on the specific genetic characteristics of the tumor cells, might explain this poor prognosis (Zhao et al., 2006).

Among the $\mathrm{CD} 4^{+}$effector T-cells, Th17 lymphocytes have also been characterized in the DLBCL microenvironment. Th17 cells are present in very small numbers in this cancer compared with other non-Hodgkin B-cell lymphomas (B-NHLs), such as small lymphocytic lymphoma (Yang et al., 2009). The B-NHL microenvironment has even fewer Th17 cells than the peripheral blood. B-NHLs can indeed induce the suppression of effector T-cell polarization, i.e. Th17, by promoting Treg polarization.

$\mathrm{CD}^{+}$T-cells infiltrate tumor-bearing brains in PCNSL (Bashir et al., 1996) as they do in DLBCL of the testis (Riemersma et al., 2005). Very little information is available about $\mathrm{CD} 4^{+}$cells in these rare tumors.

\section{$\mathrm{CDB}^{+}$T-cells are associated with a poor outcome}

$\mathrm{CD}^{+}$TILs are present in the DLBCL microenvironment. Their presence is positively linked to the loss of major histocompatibility complex (MHC) class I and II molecules from the tumor cell surface (List et al., 1993). The loss of MHC, described as a mechanism of immune escape, has been shown to be a feature of DLBCL aggressiveness (Riemersma et al., 2005). This loss of MHC class I molecules could be explained by the phenomenon of tumor editing, where $\mathrm{CD}^{+}{ }^{+} \mathrm{T}$-cells eliminate all MHC class I bearing tumor cells thereby favoring the emergence of new clones of tumor cells. Hasselblom et al. (2007) showed that a high number of activated TIA- $1^{+}$cytotoxic T-cells was correlated with poorer survival among patients (143 patients in a cohort of 195 patients). The percentage of $\mathrm{CD} 3$-positive lymphocytes with granzyme $\mathrm{B}$ expression was found to be an indicator of unfavorable prognosis in 70 patients with primary nodal DLBCL (Muris et al., 2004; Table 1). These data demonstrate that $\mathrm{CD}^{+}$cytotoxic T-cells infiltrate is a marker of poor prognosis. The relationship between the down regulation of MHC class I molecules and percentage of cytotoxic T-cells suggest possible immune-escape mechanisms in nodal DLBCL. 


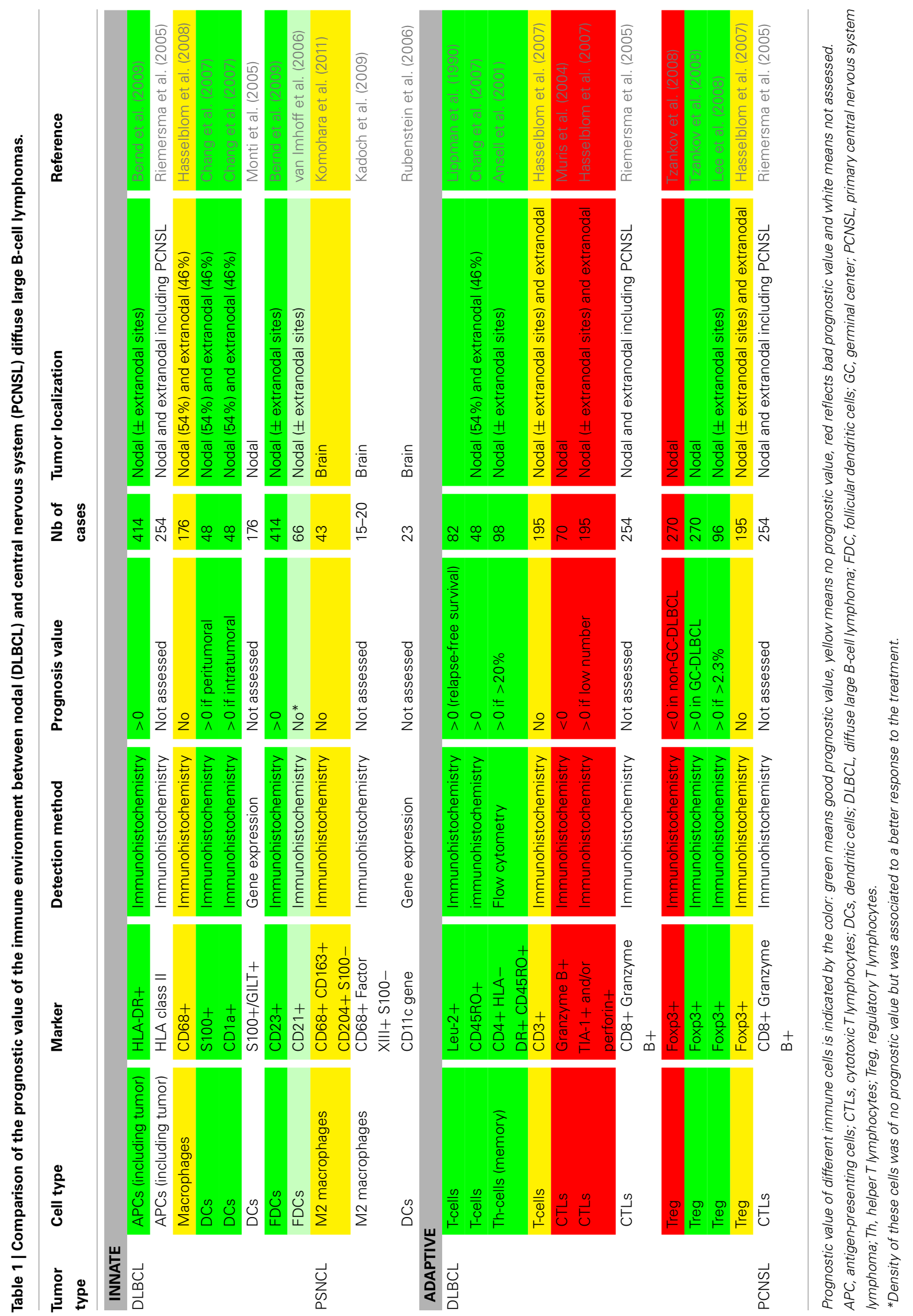


In the brain, an initial study of six patients reported the almost total absence of $\mathrm{CD}^{+}$cells in PCNSL biopsies (Bashir et al., 1996). In a more recent work, CNS lymphomas contained high densities of cytotoxic T-cells expressing granzyme B, more than in nodal DLCBLs (Riemersma et al., 2005). The authors noted that the loss of MHC class I is more common in CNS than in nodal lymphomas, and is correlated to the number of cytotoxic T-cells. It is therefore conceivable that the loss of MHC class I is the consequence of a strong selective pressure from the T-cells in PCNSL.

\section{ANTIGEN-PRESENTING CELLS \\ Dendritic cells favor the host anti-tumor response}

Data about the density of DCs and patients survival in DLBCL are sparse (reviewed in Table 1). Monti et al. (2005), molecularly profiled DLBCLs and described three subgroups, including one called the "host-response" subgroup, which was characterized by abundant immune infiltrate. The infiltrating cells included DCs that expressed both GILT (gamma interferon induced lysosomal thiol reductase) and S100 molecules and did not express either CD1a or CD123. This phenotype is characteristic of interdigitating DCs, present in secondary lymphoid organs, but not of migrating DCs, which could be recruited at the tumor site. It is indeed noteworthy that DCs are already present in lymphoid organs and are therefore ideally located to induce an anti-tumor response contrary to the extranodal tumors. The number of interdigitating DCs was highly correlated with that of infiltrating T-cells, but this study did not determine their prognostic values.

Chang et al. (2007) analyzed DCs and T-cells in DLBCL tissues by immunohistochemistry in 48 cases of DLBCL, including nodal and extranodal types. DCs were not always detected and were sparse in most cases. In $20 \%$ of the tumors however, S100 ${ }^{+}$DCs adopted a characteristic peritumoral localization that was associated with significantly better OS. The authors also found that the density of peritumoral CD45RO ${ }^{+}$T-cells, which colocalized with $\mathrm{S}_{100^{+}}$DCs was correlated with a favorable prognostic value.

The central nervous system (CNS) is naturally devoid of DCs. Some of these cells can be found in meninges, the choroid plexus, or circumventricular organs, but very few if any of these cells can be detected in healthy brain parenchyma. DCs are known to infiltrate CNS tumors such as gliomas (Morimura et al., 1990; Parney et al., 2009) or even such ocular tumors as uveal melanomas (Polak et al., 2007). Almost no study has assessed the presence of DCs in PCNSL. Interestingly however, the integrin alpha X (or CD11c) gene is reported to be expressed at significantly lower levels in PCNSL compared with nodal DLBCL (Rubenstein et al., 2006).

All these studies strongly suggest that DCs have significant value as favorable prognostic factors in DLBCLs. However, the great heterogeneity of this cell type makes it difficult to draw a clear conclusion. Further research on the specific subpopulations present and involved in the anti-tumor response would be both interesting and useful.

\section{Macrophages play ambiguous roles and lack discriminative markers}

Tumor-associated macrophages have been highlighted as key players in the tumor microenvironment in mouse models (Mantovani et al., 2011; Allavena and Mantovani, 2012). They may contribute to tumor growth via different mechanisms such as angiogenesis promotion. But macrophages can also be considered as potential APCs as they can upregulate costimulatory molecules and restimulate locally infiltrating T-cells. These cells therefore play ambiguous role.

Several studies have detected $\mathrm{CD}^{+} 8^{+}$cells, characteristic of macrophages in DLBCL. For example, DLBCLs contain substantially greater $\mathrm{CD}_{6}{ }^{+} \mathrm{CD} 14^{+}$cell populations than other B lymphomas. Interestingly, the in vitro conversion of these cells into a DC-type population suggests $\mathrm{CD} 14^{+}$cells might be DC precursors (Marmey et al., 2006). Hasselblom et al. (2008) showed that the density of $\mathrm{CD}^{+} 8^{+}$cells had no prognostic value in 176 patients with DLBCL. Another study assessed the absolute number of peripheral blood monocytes at diagnosis and reported that an elevated monocyte count was associated with a significantly poorer OS and that this finding combined with a low absolute lymphocyte count, identified a group of patients at high risk (Wilcox et al., 2011). The poor prognosis associated with high monocyte numbers may be explained by the observation that these cells are able to favor lymphoma cells survival and proliferation at least in vitro (Mueller et al., 2007).

Macrophages have been the subject of several investigations in PCNSLs. It is clear that these cells strongly invade all kinds of brain tumors, including B-cell lymphomas at least in part because the tumor cells secrete MCP-1, a macrophage chemoattractant (Kitai et al., 2007). Recent studies have demonstrated that some tumorassociated macrophages, have the alternative (or M2) phenotype, one that suggests a mainly pro-tumorigenic function (Kadoch et al., 2009). These results were confirmed by Komohara et al. (2011) who showed that most PCNSLs contained CD68 ${ }^{+}$CD204 ${ }^{+}$ and/or $\mathrm{CD}_{163}{ }^{+} \mathrm{M} 2$ macrophages and that these macrophages were correlated with high activation of the Stat 3 transcription factor known to be involved in tumor escape. Interestingly none of these markers had any prognostic significance in a series of 43 patients (Table 1).

\section{FOLLICULAR DENDRITIC CELLS}

Follicular dendritic cells (FDC) meshworks are another finding of interest. Usually, these cells reflect the global architecture of the lymph node and are associated with follicular lymphomas. However, two studies noted their presence in about $25 \%$ of the DLBCL cases analyzed, including both GCB and non-GCB subtypes and nodal and extranodal localizations. In the first study, which included 66 patients, the presence of $\mathrm{CD} 21^{+}$FDC was associated with a better treatment response rate but not with a better survival (van Imhoff et al., 2006). A larger cohort of 414 cases of DLBCLs confirmed the positive effect of FDCs, showing that the presence of $\mathrm{CD} 23^{+}$FDCs was an independent prognostic factor associated with better outcome (Bernd et al., 2009). It is not yet clear either if these meshworks represent remnants of the organ architecture or if lymphoma cells interact closely with FDCs.

As Table 1 shows, these results, taken together, highlight the strong relation between patient outcome and the composition of the immune infiltrate in DLBCLs. Thus, as for solid tumors, the prognostic value of the density of overall T-cells, of CD45RO ${ }^{+}$ memory T-cells and of DCs is good. The prognostic value of Tregs, on the other hand, depends on the genetic characterization of the 
tumor. In contrast with most types of solid tumors, however, the density of $\mathrm{CD}^{+}$T-cells is associated with a poor prognosis. In nodal DLBCL and PCNSL, high densities of $\mathrm{CD} 8^{+}$T-cells are correlated with the loss of MHC class I and II molecules and tumor aggressiveness. Indeed, the frequent loss or down regulation of MHC class I molecules occurs in many solid cancers (Campoli and Ferrone, 2008). Hence this inverse effect of CD8 ${ }^{+}$ T-cells on patient outcome might reflect the peculiar situation of $\mathrm{B}$-cell lymphomas, which are able to present antigen to MHC class II-restricted cells and activate $\mathrm{CD} 4^{+} \mathrm{T}$-cells, therefore allowing $\mathrm{T}$ cell's help and the $\mathrm{CD}^{+}$cytotoxic immune response. This might lead to a high selective pressure on tumor cells and favor escape of MHC negative tumor variants. The following concomitant loss of MHC class I and II molecules may then have a strong negative impact on the anti-tumor immune response. Interestingly, $\mathrm{CD} 8^{+}$macrophages have no prognostic value in DLBCLs, either nodal or extranodal. Studies investigating markers specific to other macrophage subtypes are needed to draw definitive conclusions. All these results are summarized in Figure 1.

\section{MOUSE MODELS}

Murine models are particularly well-suited to study the tumor microenvironment of DLBCL. Implantation of the A20 cell line in syngeneic mice produces one of the models used most often (Donnou et al., 2012). The analysis of immune infiltrate in the brain is justified by the fact that immune deficient animals die prematurely from brain B-cell lymphomas compared to their wildtype counterparts (Donnou et al., 2011), showing the existence of a spontaneous anti-tumor response. Moreover, an efficient antitumor response can be induced in PCNSL but this has been very poorly investigated until now. It has nevertheless been shown in a murine model of nude mice that celecoxib was able to induce a prolonged survival time (Wang et al., 2006), or in a syngeneic murine model that rituximab was able to induce tumor rejection in some animals (Mineo et al., 2008). But no study assessed the anti-tumor immune response associated with tumor rejection.

\section{T-CELLS}

Using a model of subcutaneous large B-cell lymphoma, Grille et al. (2010) showed that $\mathrm{CD}^{+}{ }^{+}$-cells represented most of the T-cell infiltrate (10\% Th1, 5\% Th2, and 15\% Tregs). We developed three models more relevant to human locations, specifically to tumorbearing spleen, brain, and eye. Our analysis of T-cell infiltrate showed that it was composed mainly of $\mathrm{CD} 4^{+} \mathrm{T}$-cells (Touitou et al., 2007; Donnou et al., 2011), consistent with the findings of Grille and colleagues. We also showed that Treg account for a very high proportion of the $\mathrm{CD}^{+}$T-cells $(25 \%)$ in intrasplenic lymphoma. This proportion is significantly higher in sanctuaries: $40 \%$ in the lymphoma-bearing brain (Donnou et al., 2011) and 47\% in lymphoma-bearing eyes (unpublished data). All three localizations had a Th1 and Th17 signature, but we failed to detect a Th2 profile in the PIOL microenvironment (Touitou et al., 2007). These data confirm that the privileged status of the eye is higher than that of the brain. We also demonstrated the anti-tumor activity of Th17 cells in PIOL. Th17 lymphocytes in this microenvironment produce IL-17 and IL-21. IL-21 can directly inhibit the proliferation of tumor cells (A20IIA-GFP) although IL-17 cannot (Galand et al., 2011).

The role of CTLs in lymphoma control has been highlighted by the study of Juszczynski et al. (2008). Perforin is produced by NK cells and CTLs and mice knock out for perforin develop spontaneous lymphomas more often than WT mice (incidence rate increases). These results show that NK and/or CTLs might play a role in preventing or abating lymphoma development (Smyth

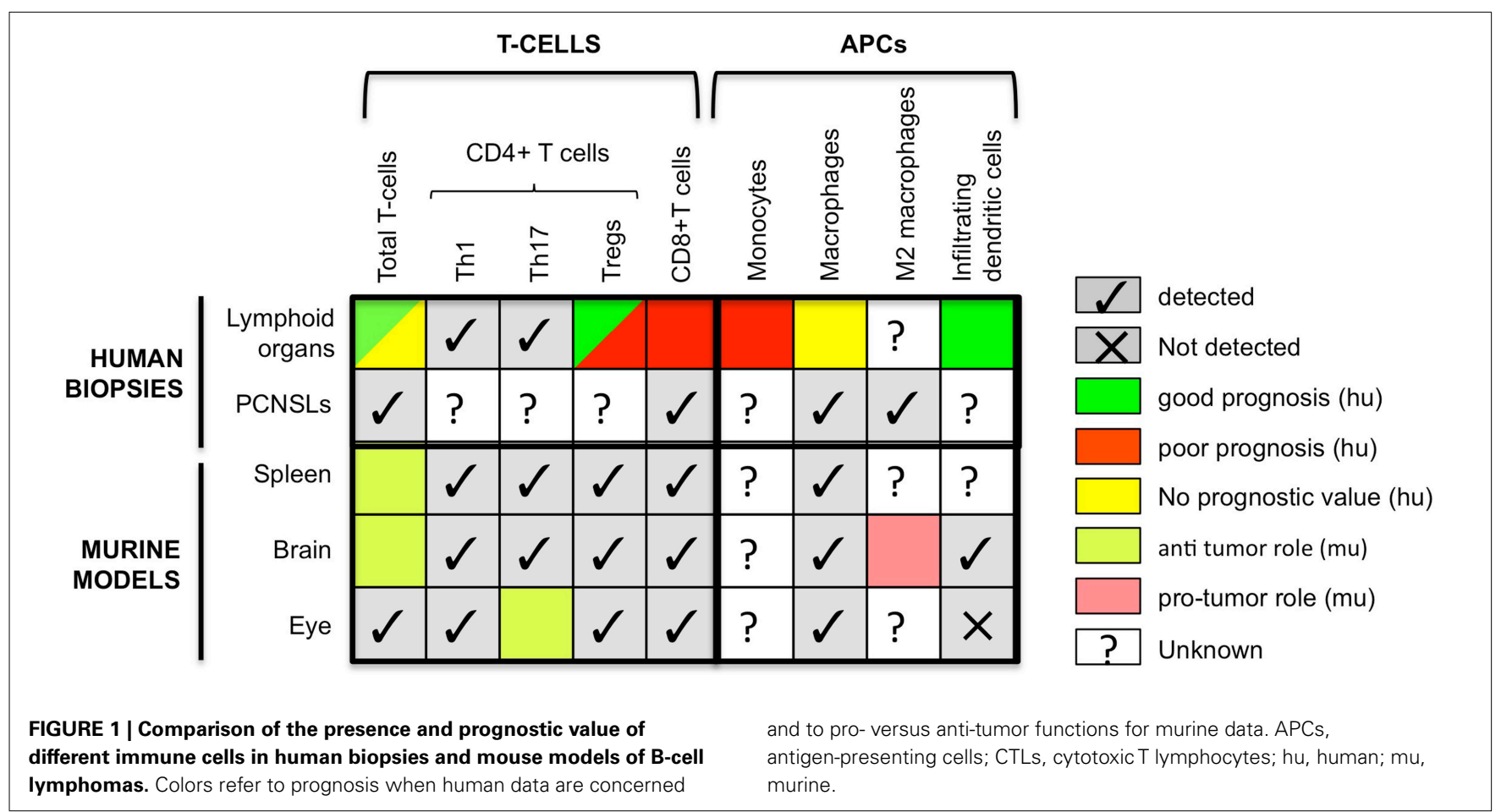


et al., 2000). Murine models are indeed particularly useful to dissect the anti-tumor immune response. As underlined here, deficient animals allow determining subpopulation functions. And it is conceivable to study $\mathrm{T}$-cell repertoire at different times during the immune response as well as MHC expression on tumor cells to determine if tumor editing is taking place.

\section{APCS HIGHLY INFILTRATE B LYMPHOMA MODELS}

We used these models to compare the immune response developing in the eye, brain and spleen after injection of tumor cells in these sites (Touitou et al., 2007; Donnou et al., 2011). $\mathrm{CD}_{11} \mathrm{~b}^{+}$macrophagic/microglial cells were detected in high numbers in all three locations, consistent with human studies and confirmed as well after subcutaneous (Palmieri et al., 2010) and intravenous (Serafini et al., 2008) injections of tumor cells. The antigen-presenting capacity of these $\mathrm{CD}_{11} \mathrm{~b}^{+}$cells was not assessed in either study. Many CD11b ${ }^{+}$macrophagic cells, have been shown to be immunosuppressive in the form of either M2type macrophages in a PCNSL model (Kadoch et al., 2009) or myeloid suppressor cells in an intravenous model (Serafini et al., 2008). The murine model allowed the authors to show that these myeloid suppressor cells act by inducing tumor antigen specific regulatory T-cells (Tregs).

$\mathrm{CD}_{11 \mathrm{c}^{+}} \mathrm{DCs}$ have also been detected in the brain and the spleen of PCNSL and intrasplenic lymphoma-bearing mice (Donnou et al., 2011). They were located mainly in the tumor mass, and their number increased with tumor growth. This study showed that there were at least two subpopulations of DCs, those that do and do not express CD11b. It is not yet known whether these cells have pro- or anti-tumor functions. Our inability to

\section{REFERENCES}

Alizadeh, A. A., Eisen, M. B., Davis, R. E., Ma, C., Lossos, I. S., Rosenwald, A., Boldrick, J. C., Sabet, H., Tran, T., Yu, X., Powell, J. I., Yang, L., Marti, G. E., Moore, T., Hudson, J. Jr., Lu, L., Lewis, D. B., Tibshirani, R., Sherlock, G., Chan, W. C., Greiner, T. C., Weisenburger, D. D., Armitage, J. O., Warnke, R., Levy, R., Wilson, W., Grever, M. R., Byrd, J. C., Botstein, D., Brown, P. O., and Staudt, L. M. (2000). Distinct types of diffuse large B-cell lymphoma identified by gene expression profiling. Nature 403, 503-511.

Allavena, P., and Mantovani, A. (2012). Immunology in the clinic review series; focus on cancer: tumour-associated macrophages: undisputed stars of the inflammatory tumour microenvironment. Clin. Exp. Immunol. 167, 195-205.

Ansell, S. M., Stenson, M., Habermann, T. M., Jelinek, D. F., and Witzig, T. E. (2001). Cd4+ T-cell immune response to large B-cell non-Hodgkin's lymphoma predicts patient outcome. J. Clin. Oncol. 19, 720-726.
Bashir, R., Chamberlain, M., Ruby, E., and Hochberg, F. H. (1996). T-cell infiltration of primary CNS lymphoma. Neurology 46, 440-444.

Bernd, H. W., Ziepert, M., Thorns, C., Klapper, W., Wacker, H. H., Hummel, M., Stein, H., Hansmann, M. L., Ott, G., Rosenwald, A., MullerHermelink, H. K., Barth, T. F., Moller, P., Cogliatti, S. B., Pfreundschuh, M., Schmitz, N., Trumper, L., Holler, S., Loffler, M., and Feller, A. C. (2009). Loss of HLA-DR expression and immunoblastic morphology predict adverse outcome in diffuse large B-cell lymphoma - analyses of cases from two prospective randomized clinical trials. Haematologica 94, 1569-1580.

Campoli, M., and Ferrone, S. (2008). HLA antigen changes in malignant cells: epigenetic mechanisms and biologic significance. Oncogene 27, 5869-5885.

Chan, C. C. (2003). Primary intraocular lymphoma: clinical features, diagnosis, and treatment. Clin. Lymphoma 4, 30-31.

Chang, K. C., Huang, G. C., Jones, D., and Lin, Y. H. (2007). Distribution patterns of dendritic cells and

detect any DCs in the PIOL model suggests that this site could be even more immune-privileged than the brain (Touitou et al., 2007). Palmieri et al. (2010) also worked with the A20 model implanted subcutaneously. Their analysis of the tumor microenvironment was clearly consistent with the studies cited above, showing large numbers of tumor-infiltrating $\mathrm{CD} 11 \mathrm{c}^{+}$cells. None of these studies, however, looked at DC subpopulations. These models might therefore be very useful to study the DCs associated with the anti-tumor response and to determine what impairs DC recruitment/differentiation in PIOLs.

In conclusion, these models have made it possible to demonstrate the strong impact that DLBCL location has on the quality and quantity of T-cell infiltrate. The proportions of Tregs in this infiltrate are higher in the ocular and CNS locations and DCs are undetectable in the ocular location. These differences most likely reflect the immunosuppressive context of the immune sanctuaries. As underlined in Figure 1, data regarding the presence of immune subpopulations in human and mouse are alike, but their functions mostly remain unknown justifying more research to now decipher their function and potential applications in new therapeutic strategies.

\section{ACKNOWLEDGMENTS}

Grant support: Our work was supported by the Institut National du Cancer (Grants RC013-C06N631-2005 and C06N748-2006), the Institut National de la Santé et de la Recherche Médicale, the University Pierre and Marie Curie, the University Paris-Descartes and the Association pour la Recherche contre le Cancer. Sabrina Donnou was recipient of a grant from the Institut National du Cancer.

$\mathrm{T}$ cells in diffuse large B-cell lymphomas correlate with prognoses. Clin. Cancer Res. 13, 6666-6672.

Chiu, B. C., and Weisenburger, D. D. (2003). An update of the epidemiology of non-Hodgkin's lymphoma. Clin. Lymphoma 4, 161-168.

Dieu-Nosjean, M. C., Antoine, M., Danel, C., Heudes, D., Wislez, M. Poulot, V., Rabbe, N., Laurans, L., Tartour, E., De Chaisemartin, L., Lebecque, S., Fridman, W. H., and Cadranel, J. (2008). Long-term survival for patients with non-small-cell lung cancer with intratumoral lymphoid structures. J. Clin. Oncol. 26, 4410-4417.

Donnou, S., Galand, C., Daussy, C., Crozet, L., Fridman, W. H., Sautes-Fridman, C., and Fisson, S. (2011). Immune adaptive microenvironment profiles in intracerebral and intrasplenic lymphomas share common characteristics. Clin. Exp. Immunol. 165, 329-337.

Donnou, S., Galand, C., Touitou, V. Sautes-Fridman, C., Fabry, Z., and Fisson, S. (2012). Murine models of B-cell lymphomas: promising tools for designing cancer therapies. $A d v$. Hematol. 2012, 701704.
Flowers, C. R., Sinha, R., and Vose, J. M. (2010). Improving outcomes for patients with diffuse large B-cell lymphoma. CA Cancer J. Clin. 60, 393-408.

Fridman, W. H., Pages, F., SautesFridman, C., and Galon, J. (2012) The immune contexture in human tumours: impact on clinical outcome. Nat. Rev. Cancer 12, 298-306.

Galand, C., Donnou, S., Crozet, L., Brunet, S., Touitou, V., Ouakrim, H., Fridman, W. H., Sautes-Fridman, C., and Fisson, S. (2011). Th17 cells are involved in the local control of tumor progression in primary intraocular lymphoma. PLoS ONE 6, e24622. doi:10.1371/journal.pone.0024622

Galon, J., Costes, A., Sanchez-Cabo, F., Kirilovsky, A., Mlecnik, B., LagorcePages, C., Tosolini, M., Camus, M., Berger, A., Wind, P., Zinzindohoue, F., Bruneval, P., Cugnenc, P. H., Trajanoski, Z., Fridman, W. H., and Pages, F. (2006). Type, density, and location of immune cells within human colorectal tumors predict clinical outcome. Science 313, 1960-1964. 
Grille, S., Brugnini, A., Nese, M., Corley, E., Falkenberg, F. W., Lens, D., and Chabalgoity, J. A. (2010). A B-cell lymphoma vaccine using a depot formulation of interleukin-2 induces potent antitumor immunity despite increased numbers of intratumoral regulatory $\mathrm{T}$ cells. Cancer Immunol. Immunother. 59, 519-527.

Groves, F. D., Linet, M. S., Travis, L. B., and Devesa, S. S. (2000). Cancer surveillance series: non-Hodgkin's lymphoma incidence by histologic subtype in the United States from 1978 through 1995. J. Natl. Cancer Inst. 92, 1240-1251.

Gurbuxani, S., Anastasi, J., and Hyjek, E. (2009). Diffuse large B-cell lymphoma - more than a diffuse collection of large B cells: an entity in search of a meaningful classification. Arch. Pathol. Lab. Med. 133, 1121-1134.

Halle, S., Dujardin, H. C., Bakocevic, N., Fleige, H., Danzer, H., Willenzon, S., Suezer, Y., Hammerling, G., Garbi, N., Sutter, G., Worbs, T., and Forster, R. (2009). Induced bronchus-associated lymphoid tissue serves as a general priming site for $\mathrm{T}$ cells and is maintained by dendritic cells. J. Exp. Med. 206, 2593-2601.

Hasselblom, S., Hansson, U., Sigurdardottir, M., Nilsson-Ehle, H., Ridell, B., and Andersson, P. O. (2008). Expression of CD68+ tumor-associated macrophages in patients with diffuse large B-cell lymphoma and its relation to prognosis. Pathol. Int. 58, 529-532.

Hasselblom, S., Sigurdadottir, M., Hansson, U., Nilsson-Ehle, H., Ridell, B., and Andersson, P. O. (2007). The number of tumour-infiltrating TIA-1+ cytotoxic $\mathrm{T}$ cells but not FOXP3+ regulatory $\mathrm{T}$ cells predicts outcome in diffuse large Bcell lymphoma. Br. J. Haematol. 137, 364-373.

Jais, J. P., Haioun, C., Molina, T. J., Rickman, D. S., De Reynies, A., Berger, F., Gisselbrecht, C., Briere, J., Reyes, F., Gaulard, P., Feugier, P., Labouyrie, E., Tilly, H., Bastard, C., Coiffier, B., Salles, G., and Leroy, K. (2008). The expression of 16 genes related to the cell of origin and immune response predicts survival in elderly patients with diffuse large B-cell lymphoma treated with CHOP and rituximab. Leukemia 22, 1917-1924.

Jordanova, E. S., Riemersma, S. A., Philippo, K., Schuuring, E., and Kluin, P. M. (2003). Beta2microglobulin aberrations in diffuse large B-cell lymphoma of the testis and the central nervous system. Int. J. Cancer 103, 393-398.

Juszczynski, P., Nowak, J., and Warzocha, K. (2008). Host immune response in B-cell lymphomas: friend or foe? Arch. Immunol. Ther. Exp. (Warsz.) 56, 245-255.

Kadoch, C., Dinca, E. B., Voicu, R., Chen, L., Nguyen, D., Parikh, S., Karrim, J., Shuman, M. A., Lowell, C. A., Treseler, P. A., James, C. D., and Rubenstein, J. L. (2009). Pathologic correlates of primary central nervous system lymphoma defined in an orthotopic xenograft model. Clin. Cancer Res. 15, 1989-1997.

Kim, M. K., Bae, S. H., Bae, Y. K., Kum, Y. S., Ryoo, H. M., Cho, H. S., Lee, K. H., Koh, S. A., Lee, H. Y., Yun, S. Y., Choi, J. H., and Hyun, M. S. (2011). Biological characterization of nodal versus extranodal presentation of diffuse large B-Cell lymphoma using immunohistochemistry. Clin. Lymphoma Myeloma Leuk. 11, 403-408.

Kitai, R., Ishisaka, K., Sato, K., Sakuma, T., Yamauchi, T., Imamura, Y., Matsumoto, H., and Kubota, T. (2007). Primary central nervous system lymphoma secretes monocyte chemoattractant protein 1. Med. Mol. Morphol. 40, 18-22.

Komohara, Y., Horlad, H., Ohnishi, K., Ohta, K., Makino, K., Hondo, H., Yamanaka, R., Kajiwara, K., Saito, T., Kuratsu, J., and Takeya, M. (2011). M2 macrophage/microglial cells induce activation of Stat 3 in primary central nervous system lymphoma. J. Clin. Exp. Hematop. 51, 93-99.

Lee, N. R., Song, E. K., Jang, K. Y., Choi, H. N., Moon, W. S., Kwon, K., Lee, J. H., Yim, C. Y., and Kwak, J. Y. (2008). Prognostic impact of tumor infiltrating FOXP3 positive regulatory $\mathrm{T}$ cells in diffuse large $\mathrm{B}$ cell lymphoma at diagnosis. Leuk. Lymphoma 49, 247-256.

Lenz, G., Wright, G., Dave, S. S., Xiao, W., Powell, J., Zhao, H., Xu, W., Tan, B., Goldschmidt, N., Iqbal, J., Vose, J., Bast, M., Fu, K., Weisenburger, D. D., Greiner, T. C., Armitage, J. O., Kyle, A., May, L., Gascoyne, R. D., Connors, J. M., Troen, G., Holte, H., Kvaloy, S., Dierickx, D., Verhoef, G., Delabie, J., Smeland, E. B., Jares, P., Martinez, A., Lopez-Guillermo, A., Montserrat, E., Campo, E., Braziel, R. M., Miller, T. P., Rimsza, L. M., Cook, J. R., Pohlman, B., Sweetenham, J., Tubbs, R. R., Fisher, R. I., Hartmann, E., Rosenwald, A., Ott, G., MullerHermelink, H. K., Wrench, D., Lister, T. A., Jaffe, E. S., Wilson, W. H., Chan, W. C., and Staudt, L. M. (2008). Stromal gene signatures in large-B-cell lymphomas. N. Engl. J. Med. 359, 2313-2323.

Lippman, S. M., Spier, C. M., Miller, T. P., Slymen, D. J., Rybski, J. A., and Grogan, T. M. (1990). Tumorinfiltrating T-lymphocytes in B-cell diffuse large cell lymphoma related to disease course. Mod. Pathol. 3, 361-367.

List, A. F., Spier, C. M., Miller, T. P., and Grogan, T. M. (1993). Deficient tumor-infiltrating T-lymphocyte response in malignant lymphoma: relationship to HLA expression and host immunocompetence. Leukemia 7, 398-403.

Lopez-Guillermo, A., Colomo, L., Jimenez, M., Bosch, F., Villamor, N., Arenillas, L., Muntanola, A., Montoto, S., Gine, E., Colomer, D., Bea, S., Campo, E., and Montserrat, E. (2005). Diffuse large B-cell lymphoma: clinical and biological characterization and outcome according to the nodal or extranodal primary origin. J. Clin. Oncol. 23, 2797-2804

Mantovani, A., Germano, G., Marchesi, F., Locatelli, M., and Biswas, S. K. (2011). Cancer-promoting tumorassociated macrophages: new vistas and open questions. Eur. J. Immunol. 41, 2522-2525.

Marmey, B., Boix, C., Barbaroux, J. B., Dieu-Nosjean, M. C., Diebold, J., Audouin, J., Fridman, W. H., Mueller, C. G., and Molina, T. J. (2006). CD14 and CD169 expression in human lymph nodes and spleen: specific expansion of CD14+CD169- monocytederived cells in diffuse large B-cell lymphomas. Hum. Pathol. 37, 68-77.

Mineo, J. F., Scheffer, A., Karkoutly, C., Nouvel, L., Kerdraon, O., Trauet, J., Bordron, A., Dessaint, J. P., Labalette, M., Berthou, C., and Labalette, P. (2008). Using human CD20transfected murine lymphomatous $B$ cells to evaluate the efficacy of intravitreal and intracerebral rituximab injections in mice. Invest. Ophthalmol. Vis. Sci. 49, 4738-4745.

Monti, S., Savage, K. J., Kutok, J. L., Feuerhake, F., Kurtin, P., Mihm, M., Wu, B., Pasqualucci, L., Neuberg, D., Aguiar, R. C., Dal Cin, P., Ladd, C., Pinkus, G. S., Salles, G., Harris, N. L., Dalla-Favera, R., Habermann, T. M., Aster, J. C., Golub, T. R., and Shipp, M. A. (2005). Molecular profiling of diffuse large B-cell lymphoma identifies robust subtypes including one characterized by host inflammatory response. Blood 105, 1851-1861.

Morimura, T., Neuchrist, C., Kitz K., Budka, H., Scheiner, O., Kraft,
D., and Lassmann, H. (1990). Monocyte subpopulations in human gliomas: expression of $\mathrm{Fc}$ and complement receptors and correlation with tumor proliferation. Acta Neuropathol. 80, 287-294.

Mueller, C. G., Boix, C., Kwan, W. H., Daussy, C., Fournier, E., Fridman, W. H., and Molina, T. J. (2007). Critical role of monocytes to support normal B cell and diffuse large B cell lymphoma survival and proliferation. J. Leukoc. Biol. 82, 567-575.

Muris, J. J., Meijer, C. J., Cillessen, S. A., Vos, W., Kummer, J. A., Bladergroen, B. A., Bogman, M. J., Mackenzie, M. A., Jiwa, N. M., Siegenbeek Van Heukelom, L. H., Ossenkoppele, G. J., and Oudejans, J. J. (2004). Prognostic significance of activated cytotoxic T-lymphocytes in primary nodal diffuse large B-cell lymphomas. Leukemia 18, 589-596.

Pages, F., Kirilovsky, A., Mlecnik, B., Asslaber, M., Tosolini, M., Bindea, G., Lagorce, C., Wind, P., Marliot, F., Bruneval, P., Zatloukal, K., Trajanoski, Z., Berger, A., Fridman, W. H., and Galon, J. (2009). In situ cytotoxic and memory $\mathrm{T}$ cells predict outcome in patients with early-stage colorectal cancer. J. Clin. Oncol. 27, 5944-5951.

Palmieri, C., Falcone, C., Iaccino, E., Tuccillo, F. M., Gaspari, M., Trimboli, F., De Laurentiis, A., Luberto, L., Pontoriero, M., Pisano, A., Vecchio, E., Fierro, O., Panico, M. R. Larobina, M., Gargiulo, S., Costa, N., Dal Piaz, F., Schiavone, M., Arra, C., Giudice, A., Palma, G., Barbieri, A., Quinto, I., and Scala, G. (2010). In vivo targeting and growth inhibition of the A20 murine B-cell lymphoma by an idiotypespecific peptide binder. Blood 116, 226-238.

Parney, I. F., Waldron, J. S., and Parsa, A. T. (2009). Flow cytometry and in vitro analysis of human gliomaassociated macrophages. Laboratory investigation. J. Neurosurg. 110, 572-582.

Polak, M. E., Borthwick, N. J., Johnson, P., Hungerford, J. L., Higgins, B., Di Palma, S., Jager, M. J., and Cree, I. A. (2007). Presence and phenotype of dendritic cells in uveal melanoma. Br. J. Ophthalmol. 91, 971-976.

Riemersma, S. A., Oudejans, J. J., Vonk, M. J., Dreef, E. J., Prins, F. A., Jansen, P. M., Vermeer, M. H., Blok, P., Kibbelaar, R. E., Muris, J. J., Schuuring, E. M., and Kluin, P. M. (2005). High numbers of tumourinfiltrating activated cytotoxic $\mathrm{T}$ 
lymphocytes, and frequent loss of HLA class I and II expression, are features of aggressive B cell lymphomas of the brain and testis. $J$. Pathol. 206, 328-336.

Rosenwald, A., Wright, G., Leroy, K., Yu, X., Gaulard, P., Gascoyne, R. D., Chan, W. C., Zhao, T., Haioun, C., Greiner, T. C., Weisenburger, D. D., Lynch, J. C., Vose, J., Armitage, J. O., Smeland, E. B., Kvaloy, S., Holte, H., Delabie, J., Campo, E., Montserrat, E., Lopez-Guillermo, A., Ott, G., Muller-Hermelink, H. K., Connors, J. M., Braziel, R., Grogan, T. M., Fisher, R. I., Miller, T. P., Leblanc, M., Chiorazzi, M., Zhao, H., Yang, L., Powell, J., Wilson, W. H., Jaffe, E. S., Simon, R., Klausner, R. D., and Staudt, L. M. (2003). Molecular diagnosis of primary mediastinal B cell lymphoma identifies a clinically favorable subgroup of diffuse large B cell lymphoma related to Hodgkin lymphoma. J. Exp. Med. $198,851-862$.

Rubenstein, J. L., Fridlyand, J., Shen, A., Aldape, K., Ginzinger, D., Batchelor, T., Treseler, P., Berger, M., Mcdermott, M., Prados, M., Karch, J., Okada, C., Hyun, W., Parikh, S., Haqq, C., and Shuman, M. (2006). Gene expression and angiotropism in primary CNS lymphoma. Blood 107, 3716-3723.

Schaffel, R., Morais, J. C., Biasoli, I., Lima, J., Scheliga, A., Romano, S., Milito, C., and Spector, N. (2007). PKC-beta II expression has prognostic impact in nodal diffuse large B-cell lymphoma. Mod. Pathol. 20, 326-330.
Serafini, P., Mgebroff, S., Noonan, K., and Borrello, I. (2008). Myeloidderived suppressor cells promote cross-tolerance in B-cell lymphoma by expanding regulatory $\mathrm{T}$ cells. Cancer Res. 68, 5439-5449.

Shibamoto, Y., Ogino, H., Suzuki, G., Takemoto, M., Araki, N., Isobe, K., Tsuchida, E., Nakamura, K., Kenjo, M., Suzuki, K., Hosono, M., Tokumaru, S., Ishihara, S., Kato, E., Ii, N., and Hayabuchi, N. (2008). Primary central nervous system lymphoma in Japan: changes in clinical features, treatment, and prognosis during 1985-2004. Neuro-oncology $10,560-568$.

Smyth, M. J., Thia, K. Y., Street, S. E., Macgregor, D., Godfrey, D. I., and Trapani, J. A. (2000). Perforin-mediated cytotoxicity is critical for surveillance of spontaneous lymphoma. J. Exp. Med. 192, 755-760.

Touitou, V., Daussy, C., Bodaghi, B., Camelo, S., De Kozak, Y., Lehoang, P., Naud, M. C., Varin, A., Thillaye-Goldenberg, B., MerleBeral, H., Fridman, W. H., SautesFridman, C., and Fisson, S. (2007). Impaired th1/tcl cytokine production of tumor-infiltrating lymphocytes in a model of primary intraocular B-cell lymphoma. Invest. Ophthalmol. Vis. Sci. 48, 3223-3229.

Tzankov, A., Meier, C., Hirschmann, P., Went, P., Pileri, S. A., and Dirnhofer, S. (2008). Correlation of high numbers of intratumoral FOXP3+ regulatory $\mathrm{T}$ cells with improved survival in germinal center-like diffuse large B-cell lymphoma, follicular lymphoma and classical Hodgkin's lymphoma. Haematologica 93, 193-200.

van Imhoff, G. W., Boerma, E. J., Van Der Holt, B., Schuuring, E., Verdonck, L. F., Kluin-Nelemans, H. C., and Kluin, P. M. (2006). Prognostic impact of germinal centerassociated proteins and chromosomal breakpoints in poor-risk diffuse large B-cell lymphoma. J. Clin. Oncol. 24, 4135-4142.

Wang, W., Kardosh, A., Su, Y. S. Schonthal, A. H., and Chen, T. C. (2006). Efficacy of celecoxib in the treatment of CNS lymphomas: an in vivo model. Neurosurg. Focus 21, E14.

Wilcox, R. A., Ristow, K., Habermann, T. M., Inwards, D. J., Micallef, I. N., Johnston, P. B., Colgan, J. P., Nowakowski, G. S., Ansell, S. M., Witzig, T. E., Markovic, S. N., and Porrata, L. (2011). The absolute monocyte and lymphocyte prognostic score predicts survival and identifies high-risk patients in diffuse large-B-cell lymphoma. Leukemia 25, 1502-1509.

Yang, Z. Z., Novak, A. J., Stenson, M. J., Witzig, T. E., and Ansell, S. M. (2006). Intratumoral CD4+CD25+ regulatory T-cell-mediated suppression of infiltrating CD4+ $\mathrm{T}$ cells in B-cell non-Hodgkin lymphoma. Blood 107, 3639-3646.

Yang, Z. Z., Novak, A. J., Ziesmer, S. C., Witzig, T. E., and Ansell, S. M. (2009). Malignant B cells skew the balance of regulatory $\mathrm{T}$ cells and TH17 cells in B-cell
non-Hodgkin's lymphoma. Cancer Res. 69, 5522-5530.

Zhao, D. M., Thornton, A. M., Dipaolo, R. J., and Shevach, E. M. (2006). Activated $\mathrm{CD} 4+\mathrm{CD} 25+\mathrm{T}$ cells selectively kill B lymphocytes. Blood 107, 3925-3932.

Zucca, E. (2008). Extranodal lymphoma: a reappraisal. Ann. Oncol. 19(Suppl. 4), iv77-iv80.

Conflict of Interest Statement: The authors declare that the research was conducted in the absence of any commercial or financial relationships that could be construed as a potential conflict of interest.

Received: 16 February 2012; paper pending published: 01 March 2012; accepted: 14 April 2012; published online: 04 May 2012.

Citation: Galand C, Donnou S, Molina TJ, Fridman WH, Fisson S and SautèsFridman C (2012) Influence of tumor location on the composition of immune infiltrate and its impact on patient survival. Lessons from DCBCL and animal models. Front. Immun. 3:98. doi: 10.3389/fimmu.2012.00098

This article was submitted to Frontiers in Tumor Immunity, a specialty of Frontiers in Immunology.

Copyright (c) 2012 Galand, Donnou, Molina, Fridman, Fisson and SautèsFridman. This is an open-access article distributed under the terms of the Creative Commons Attribution Non Commercial License, which permits noncommercial use, distribution, and reproduction in other forums, provided the original authors and source are credited. 